\title{
Impact of collateral circulation status on favorable outcomes in thrombolysis treatment: A systematic review and meta-analysis
}

\author{
ALIMU WUFUER $^{1}$, ATIKAIMU WUBULI ${ }^{2}$, PEIERDUN MIJITI ${ }^{2}$, JUN ZHOU ${ }^{1}$, \\ SHABIER TUERXUN ${ }^{1}$, JIAN CAI $^{1}$, JIANHUA MA $^{1}$ and XIAONING ZHANG ${ }^{3}$ \\ ${ }^{1}$ Department of Neurology, The First Affiliated Hospital, Xinjiang Medical University, \\ Urumqi, Xinjiang 830054; ${ }^{2}$ Department of Epidemiology and Biostatistics, School of Public Health, \\ Xinjiang Medical University, Urumqi, Xinjiang $830011 ;{ }^{3}$ Department of Neurology, The Xinjiang Uygur \\ Autonomous Region Hospital of Traditional Chinese Medicine, Urumqi, Xinjiang 830054, P.R. China
}

Received May 2, 2017; Accepted September 1, 2017

DOI: $10.3892 / \mathrm{etm} .2017 .5486$

\begin{abstract}
Collateral circulation affects the prognosis of patients with acute ischemic stroke (AIS) treated by thrombolysis. The present study performed a systematic assessment of the impact of the collateral circulation status on the outcomes of patients receiving thrombolysis treatment. Relevant full-text articles from the Cochrane Library, Ovid, Medline, Embase and PubMed databases published from January 1, 2000 to November 1, 2016 were retrieved. The quality of the studies was assessed and data were extracted by 2 independent investigators. The random-effects model was used to estimate the impact of good vs. poor collateral circulation, as well as baseline characteristics, on the outcome within the series presented as risk ratios. Subgroup analyses explored the potential factors that may interfere with the effects of the collateral circulation status on the outcome. A total of 29 studies comprising 4,053 patients were included in the present meta-analysis. A good collateral circulation status was revealed to have a beneficial effect on favorable functional outcome (modified Rankin scale, 0-3 at 3-6 months; $\mathrm{P}<0.001$ ) and a higher rate of recanalization $(\mathrm{P}<0.001)$ compared with poor collateral circulation. Good collateral circulation was also associated with a lower rate of symptomatic intracranial hemorrhage $(\mathrm{P}<0.01)$, a lower rate of mortality $(\mathrm{P}<0.01)$ and a smaller infarct size $(\mathrm{P}<0.01)$. In conclusion, good collateral circulation was demonstrated to have a favorable prognostic value regarding the outcome for patients with AIS receiving thrombolysis treatment. Assessment of collateral circulation and penumbra area during pre-treatment imaging within an
\end{abstract}

Correspondence to: Dr Xiaoning Zhang, Department of Neurology, The Xinjiang Uygur Autonomous Region Hospital of Traditional Chinese Medicine, 137 Liyushan South Road, Urumqi, Xinjiang 830054, P.R. China

E-mail: 840296810@qq.com

Key words: thrombolysis, collateral circulation, acute ischemic stroke, systematic review and meta-analysis appropriate time-window prior to thrombolytic therapy will therefore improve the identification of AIS patients who may benefit from thrombolysis treatment.

\section{Introduction}

Stroke is a severe health issue worldwide. Available treatments are limited and it is currently the second leading cause of death (1). Prompt thrombolytic therapy is critical for improving the clinical prognosis of patients with acute ischemic stroke (AIS). The collateral circulation is a major factor affecting the effect of thrombolytic therapy and good collateral circulation significantly influences the prognosis of patients, thereby preventing and delaying permanent neurological damage (2). The collateral circulation maintains the blood supply to the infarction area prior to recanalization after AIS (3). It also prevents the expansion of the infarct size, provides a better clinical prognosis, increases the rate of recanalization and potentially prolongs the time window prior to the requirement of endovascular treatment (ET) (4-7). In addition, good collateral circulation reduces the risk of hemorrhagic transformation (HT) and mortality after thrombolysis therapy (8).

A previous systematic review by Leng et al (9) analyzed the available evidence on the correlations between collateral circulation and the outcomes in patients with AIS following intravenous thrombolysis therapy (IVT). However, it did not include studies in which endovascular treatment was used. In the present study, the relevant literature published until November 2016 was systematically reviewed and a meta-analysis was performed to evaluate the association between collateral circulation determined prior to thrombolytic treatment and outcomes.

\section{Materials and methods}

Reporting and definitions. The relevant studies were reported according to the Preferred Reporting Items for Systematic Reviews and Meta-Analyses and the Meta-Analysis of Observational Studies in Epidemiology (10,11). The definition of good or poor collateral circulation status prior to treatment was in accordance with that in the primary studies; for studies 
classifying the collateral status in $>2$ categories, it was categorized as good and poor in the present analysis by adopting the dichotomization methods from other primary studies using the same imaging modality to gauge the collateral status. The outcomes, including good recanalization/reperfusion, HT, final infarct size, mortality and the favorable functional outcome at 3-6 months, were defined in the studies.

Information sources. Potentially eligible studies as full-text articles, published from January 2000 to November 2016, were identified through a search of the Cochrane Library, Ovid, Embase, Medline and PubMed databases. The search was restricted to articles published in English language. In brief, the search terms included 'stroke', 'collateral', 'thrombolysis', 'thromboly' and 'endovascular'. A manual search was also performed by checking the references of pertinent review articles and relevant original research articles.

Study selection and eligibility criteria. The criteria for the included studies were as follows: i) Case-control, cohort or randomized controlled trial (RCT) studies on patients ( $>18$ years of age) with acute ischemic stroke; ii) collateral circulation status was evaluated prior to the initiation of thrombolysis treatment; iii) The correlation between pre-treatment collateral circulation status and outcome in patients with AIS was described. Animal studies, non-RCTs and duplicate reports were excluded.

Data collection and parameters. All titles and abstracts were initially screened by one investigator to identify potentially relevant studies for inclusion. Relevant studies were retrieved in full text and reassessed by two researchers to determine the eligibility for inclusion with regard to publication characteristics, study populations, patient demographics, onset-to-treatment time, mode of thrombolysis therapy, methods to assess the collateral circulation status, methods to define successful reperfusion and/or recanalization and definition of HT.

Statistical analysis. Cochrane RevMan (version 5.3; The Cochrane Institute, London, UK) was used for analyzing the data. The impact of good vs. poor pre-treatment collateral circulation on the outcomes was evaluated by a fixed-effects model if the heterogeneity was low or the random-effects model with the results expressed as the risk ratio (RR) and 95\% confidence interval (CI). For the clinical or imaging outcomes, subgroup analyses were performed with stratification by different sample sizes, prescribed durations of thrombolysis treatment, median baseline National Institutes of Health Stroke Scale (NIHSS), treatment type and mean (or median) age. To assess the publication bias, a visual inspection of the funnel plot was applied in the analysis of any assessed variable.

Inter-study and -subgroup heterogeneities were evaluated by $\chi^{2}$ and $\mathrm{I}^{2}$ statistics $\left(\mathrm{P}<0.10\right.$ and $\mathrm{I}^{2}>50 \%$ was considered to indicate significant heterogeneity). A sensitivity analysis was also performed by removing individual trials from the meta-analysis.

\section{Results}

Study selection and characteristics. The selection of the studies identified through the literature search was

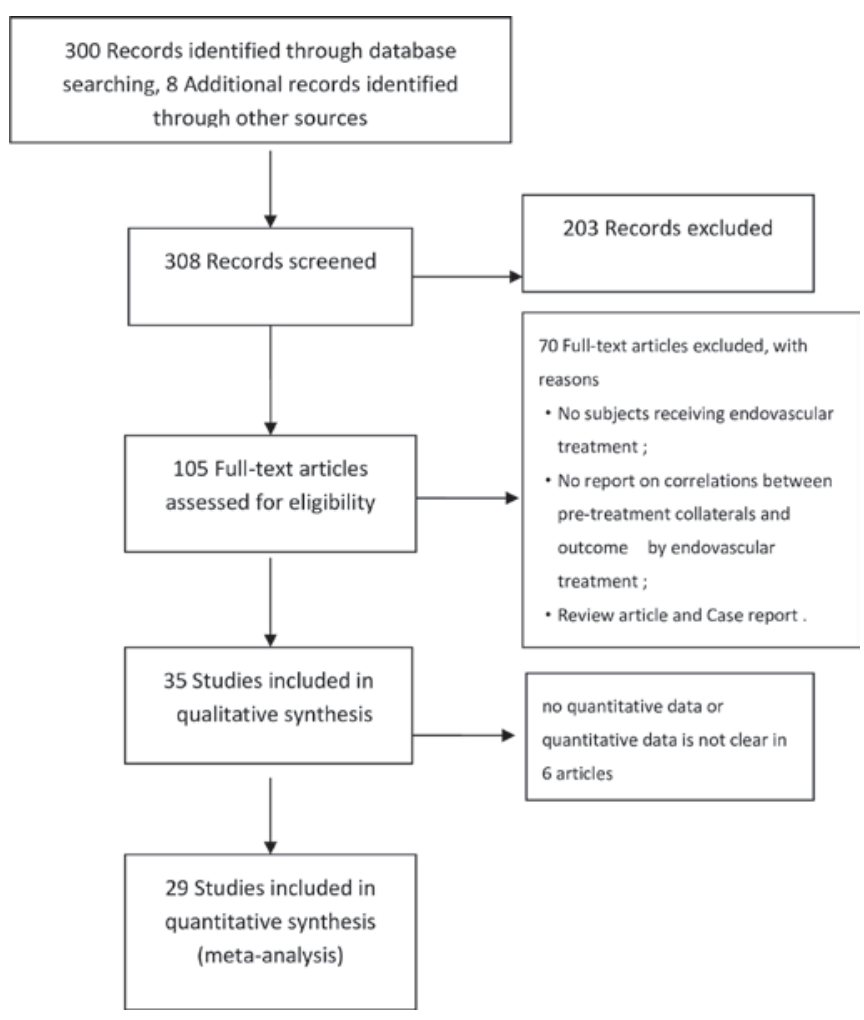

Figure 1. Schematic representation of the screening and selection of studies for inclusion in the present meta-analysis.

schematically represented in a flowchart illustrated in Fig. 1. Of the 308 records retrieved from several databases and manual searches, 29 primary studies comprising 4,053 subjects were included in the systematic review, of which 12 were retrospective studies, 17 were prospective studies, 7 were multicenter studies and 22 were single-center studies. A total of 9 studies described the treatment with IVT alone, and in the other 20 studies, patients received IVT with subsequent ET or ET only (Table I) $(7,8,12-38)$. All of the studies used tissue plasminogen activator for the thrombolysis treatment, while that by Christoforidis et al (7) used tissue plasminogen activator, urokinase and pro-urokinase. The duration of thrombolysis treatment was 3-6 h in 12 studies and $>6 \mathrm{~h}$ in 5 studies, extending up to $12 \mathrm{~h}$. However, the time window was not prescribed in 6 of the studies. The assessment of the pre-treatment collateral circulation status was performed using different imaging methods, which were computed tomography (CT) angiography in 22 studies $(7,8,12,14,15,17,18,22-35,37)$, while others included digital subtraction angiography $(13,36)$, fluid-attenuated inversion recovery imaging $(19,21)$, and CT or magnetic resonance perfusion imaging $(16,20,38)$ (Table I).

Favorable functional outcome. The present review included 22 studies (comprising 2,608 subjects) that reported on functional outcome. The rate of favorable functional outcome [modified Rankin scale (mRS) 0-3 at 3-6 months] was doubled in the GC statue group as compared with that in the $\mathrm{PC}$ group $(\mathrm{RR}=2.33 ; 95 \% \mathrm{CI}, 1.95-2.78 ; \mathrm{P}<0.001$; Fig. 2). This effect of good collateral circulation did not differ significantly between the studies (Cochran's $Q=36.47$; $\mathrm{P}=0.02 ; \mathrm{I}^{2}=42 \%$ ). In the subgroup analyses presented in 


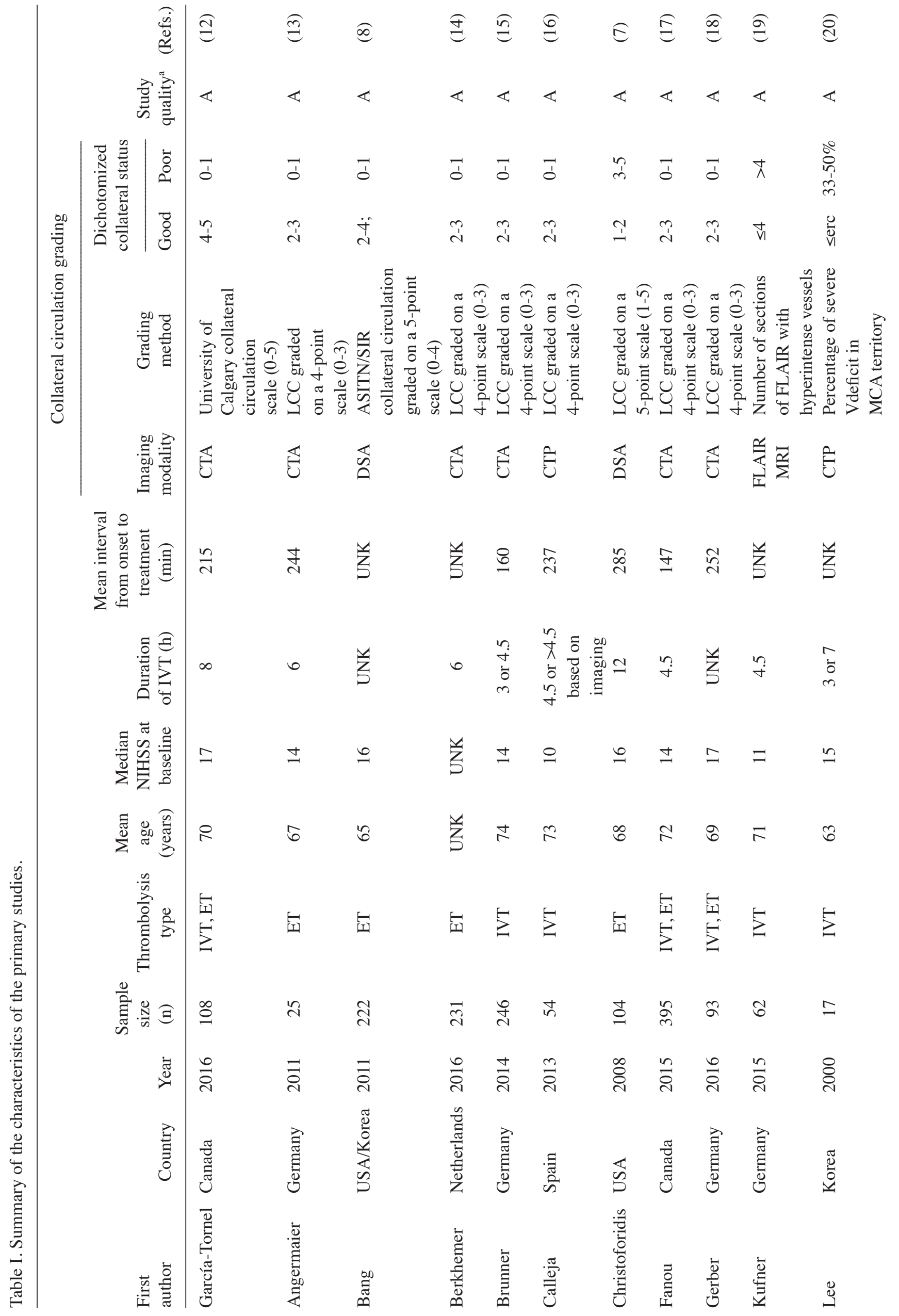




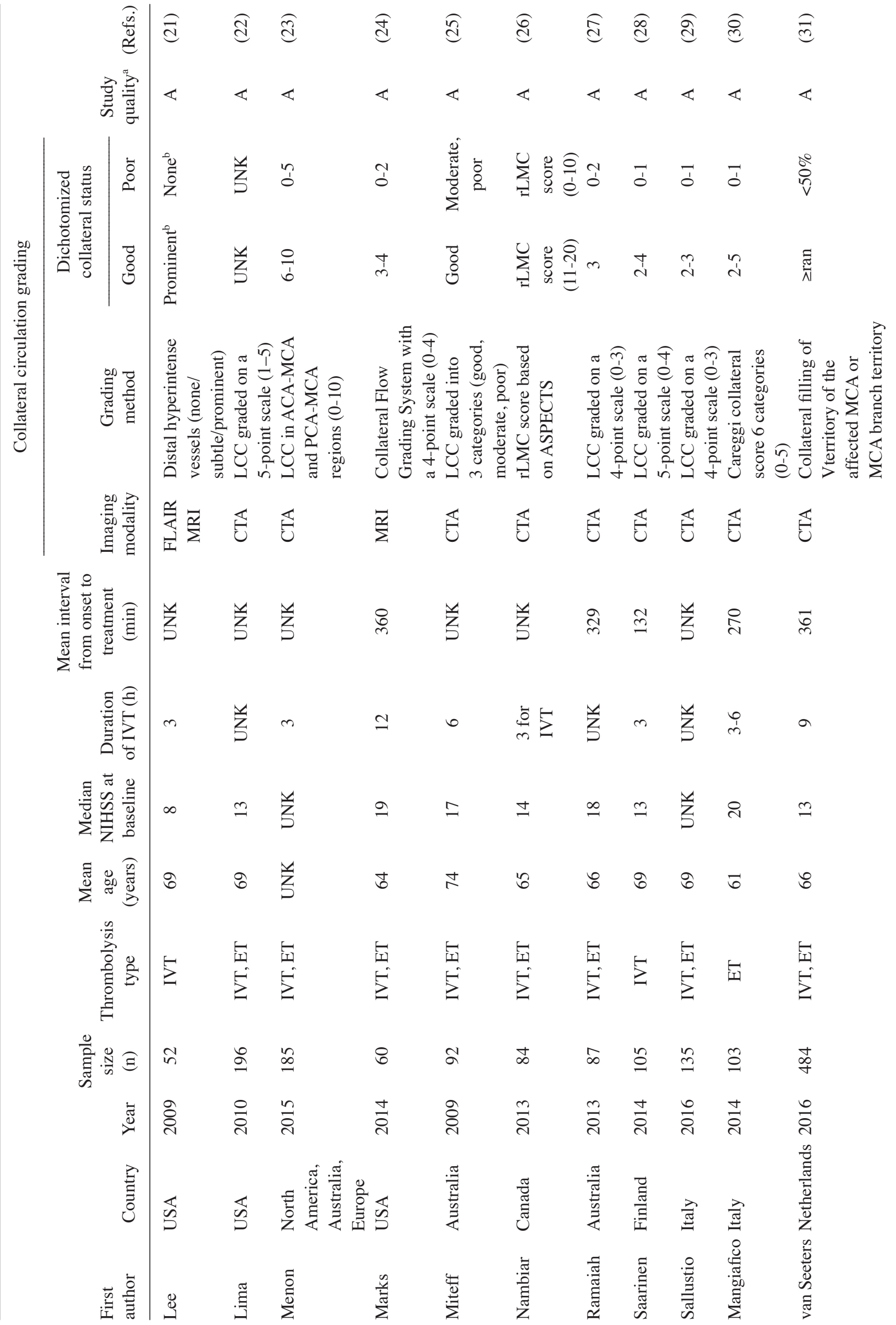




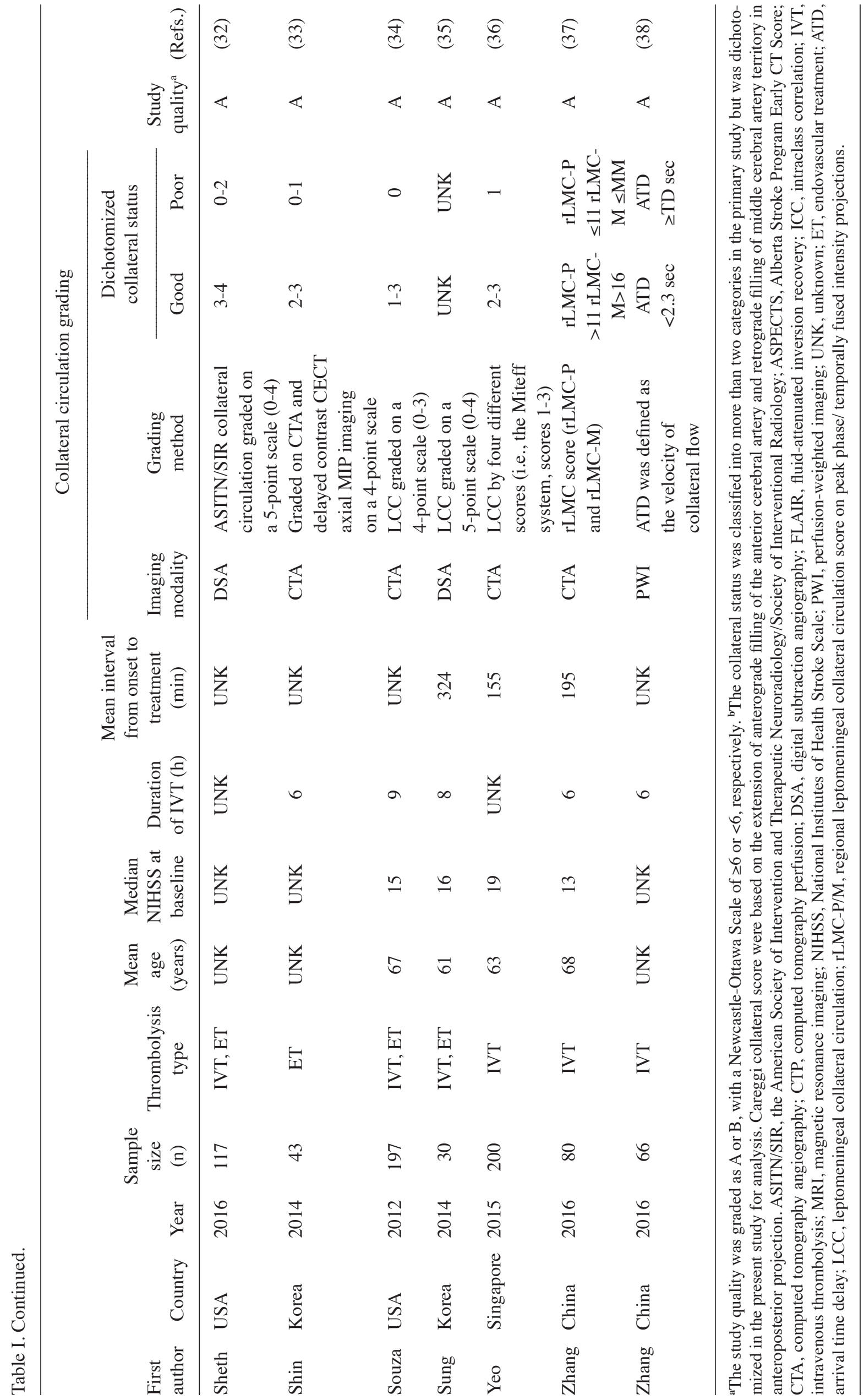




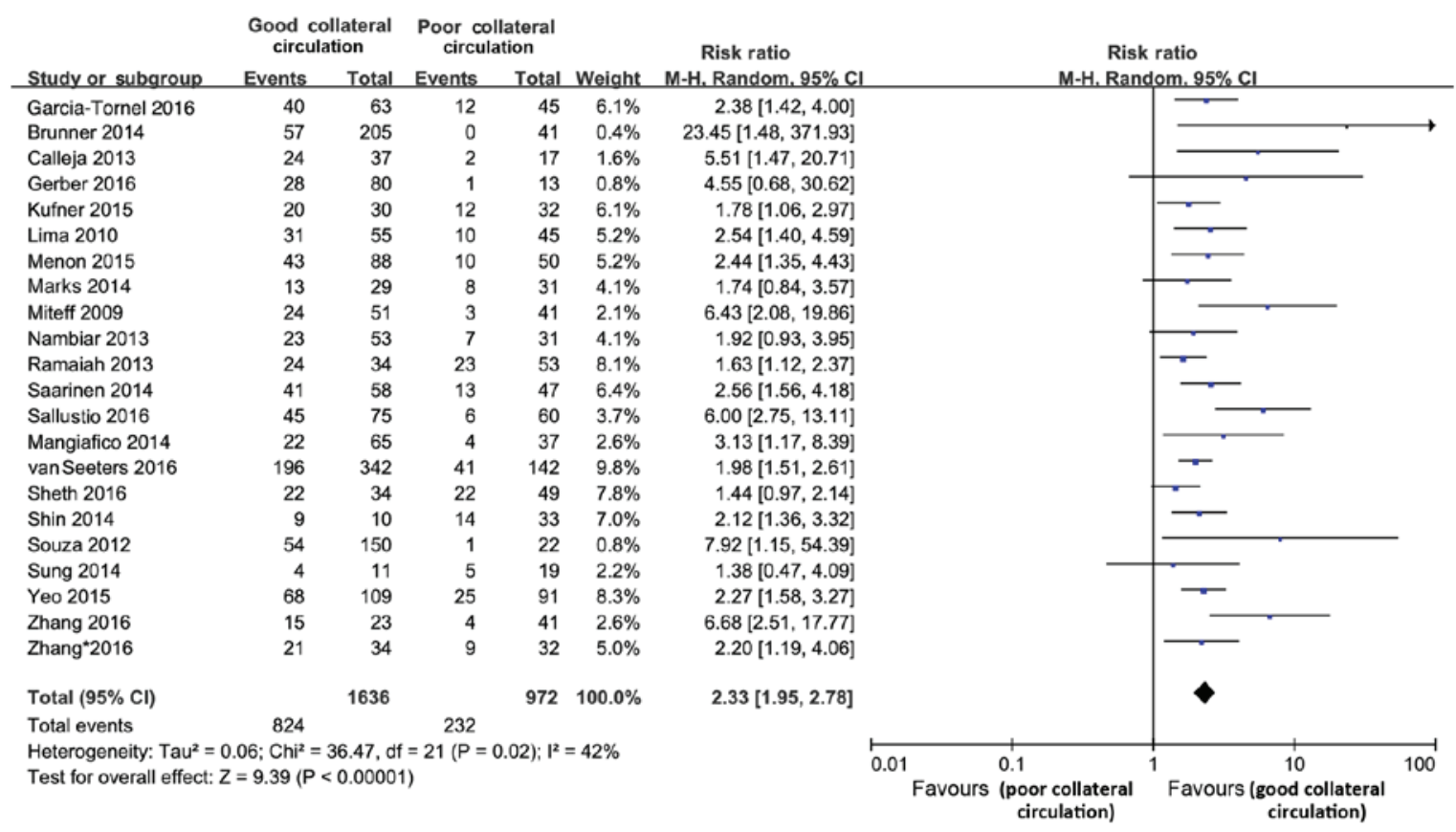

Figure 2. Forest plot presenting the estimation of the overall effect of good vs. poor pre-treatment collateral circulation status on primary outcome, a favorable functional outcome at 3 or 6 months, in patients with AIS receiving thrombolysis therapy in 23 studies. The studies are aligned by the effect size. A favorable functional outcome was defined as an mRS of 0-2 at 3 months in 19 studies, mRS of 0-1 at 3 or 6 months in the study by Yeo et al (36), mRS of 0-3 at 3 months in the study by Sheth et al (32) and mRS of 0-2 at 6 months in the study by Lima et al (22). CI, confidence interval; M-H, Mantel-Haenszel; mRS, modified Rankin Scale; df, degrees of freedom.

Table II, the beneficial effect of good collateral circulation did not differ significantly between the subgroups of studies stratified by a median NIHSS at baseline of $\leq$ or $>13$ (Cochran's $\mathrm{Q}=0.48 ; \mathrm{P}=0.49 ; \mathrm{I}^{2}=0 \%$ ); a sample size of $<$ or $\geq 100$ subjects (Cochran's $\mathrm{Q}=1.56 ; \mathrm{P}=0.21 ; \mathrm{I}^{2}=35.8 \%$ ); a mean (or median) age of $<$ or $\geq 70$ years (Cochran's $\mathrm{Q}=1.94 ; \mathrm{P}=0.16$; $\mathrm{I}^{2}=48.6 \%$ ); treatment type (IVT alone, IVT+ET or ET alone; Cochran's Q=0.75; $\left.\mathrm{P}=0.69 ; \mathrm{I}^{2}=0 \%\right)$; or duration of IVT treatment $(4.5,4.5-6 \mathrm{~h}$ or $>6$ h; Cochran's $\mathrm{Q}=2.46 ; \mathrm{P}=0.29 ; \mathrm{I}^{2}=18.6 \%$ ).

$H T$. In 8 of the studies $(12,13,15,29,30,33,36,37)$, HT was defined as symptomatic intracranial hemorrhage in cases with a 4-fold increase in the NIHSS score (ECASS II study) (39), while it was defined differently in 3 studies $(7,16,24)$; however, the definition was unclear in the 4 remaining studies $(8,20,27,32)$. In a total of 1,436 subjects, HT was evaluated from any follow-up $\mathrm{CT}$ or magnetic resonance imaging performed within $24 \mathrm{~h}$ after treatment until the time-point of discharge. The risk of HT was decreased in the pretreatment good collateral circulation group ( $R R=0.57$; 95\% CI, 0.48-0.68; P<0.001; Fig. 3), and no significant heterogeneity was observed between studies in the analysis of HT (Cochran's Q=17.21, $\mathrm{P}=0.25$; $\mathrm{I}^{2}=19 \%$ ) (Fig. 3). Subgroup analyses were performed to assess the outcomes of the different treatment types in patients with good and poor collateral circulation (Table III). The most significant effect was observed in patients administered IVT treatment alone (Cochran's $\mathrm{Q}=6.63$; $\mathrm{P}=0.04 ; \mathrm{I} 2=69.8 \%$ ). The RRs of good vs. poor collateral status for HT were $0.43,0.47$ and 0.73 for studies with treatment types IVT alone, IVT and ET and ET alone, respectively.

Mortality. The present review included 9 studies $(1,108$ subjects) that assed mortality. Compared with the PC group, a good collateral circulation status significantly lowered the risk of mortality by thrombolysis treatment $(\mathrm{RR}=0.29,95 \% \mathrm{CI}$, 0.22-0.37; $\mathrm{P}<0.01)$. This effect differed significantly between the studies (Cochran's $\mathrm{Q}=16.41 ; \mathrm{P}=0.04 ; \mathrm{I}^{2}=51 \%$ ). According to the subgroup analyses, such effects were more significant in studies with a sample size of $<100$ subjects (Cochran's $\mathrm{Q}=6.07 ; \mathrm{P}=0.01$; $\mathrm{I}^{2}=83.5 \%$ ), as the RRs of good vs. poor collateral circulation status for mortality were 0.17 and 0.37 , respectively (Fig. 4).

Recanalization or reperfusion. The present review included 13 studies (comprising 1,265 subjects) that reported on recanalization or reperfusion. In comparison with the poor collateral circulation status, good collateral circulation was significantly associated with elevated the rates of good recanalization/reperfusion $(\mathrm{RR}=1.42 ; 95 \% \mathrm{CI}, 1.20-1.68 ; \mathrm{P}<0.001$; Fig. 5), and this effect was significantly different between the studies (Cochran's $\mathrm{Q}=20.33 ; \mathrm{P}=0.06 ; \mathrm{I}^{2}=41 \%$ ). According to the subgroup analyses, such effects were more significant in studies with successful recanalization (thrombolysis in cerebral infarction score of $2 \mathrm{~b} / 3$ or other definitions; Cochran's $\mathrm{Q}=6.97 ; \mathrm{P}=0.008 ; \mathrm{I}^{2}=85.7 \%$; Fig. 5).

Final infarct volume. The final infarct volume was determined by diffusion-weighted imaging in the studies by Sheth et al (32) and Lee et al (21) and by CT in the studies by García-Tornel et al (12) and Angermaier et al (13). The good collateral circulation group displayed a significantly lower final infarct volume than the poor collateral circulation group [mean difference $=-100.11 ; 95 \%$ CI, -(118.97-81.25); $\mathrm{P}<0.01$ ]; however, no significant heterogeneity was identified between the studies (Cochran's $\mathrm{Q}=2.57 ; \mathrm{P}=0.046 ; \mathrm{I}^{2}=0 \%$ ) or between the subgroups (Cochran's $\mathrm{Q}=0.87 ; \mathrm{P}=0.35 ; \mathrm{I}^{2}=0 \%$ ) (Fig. 6). 


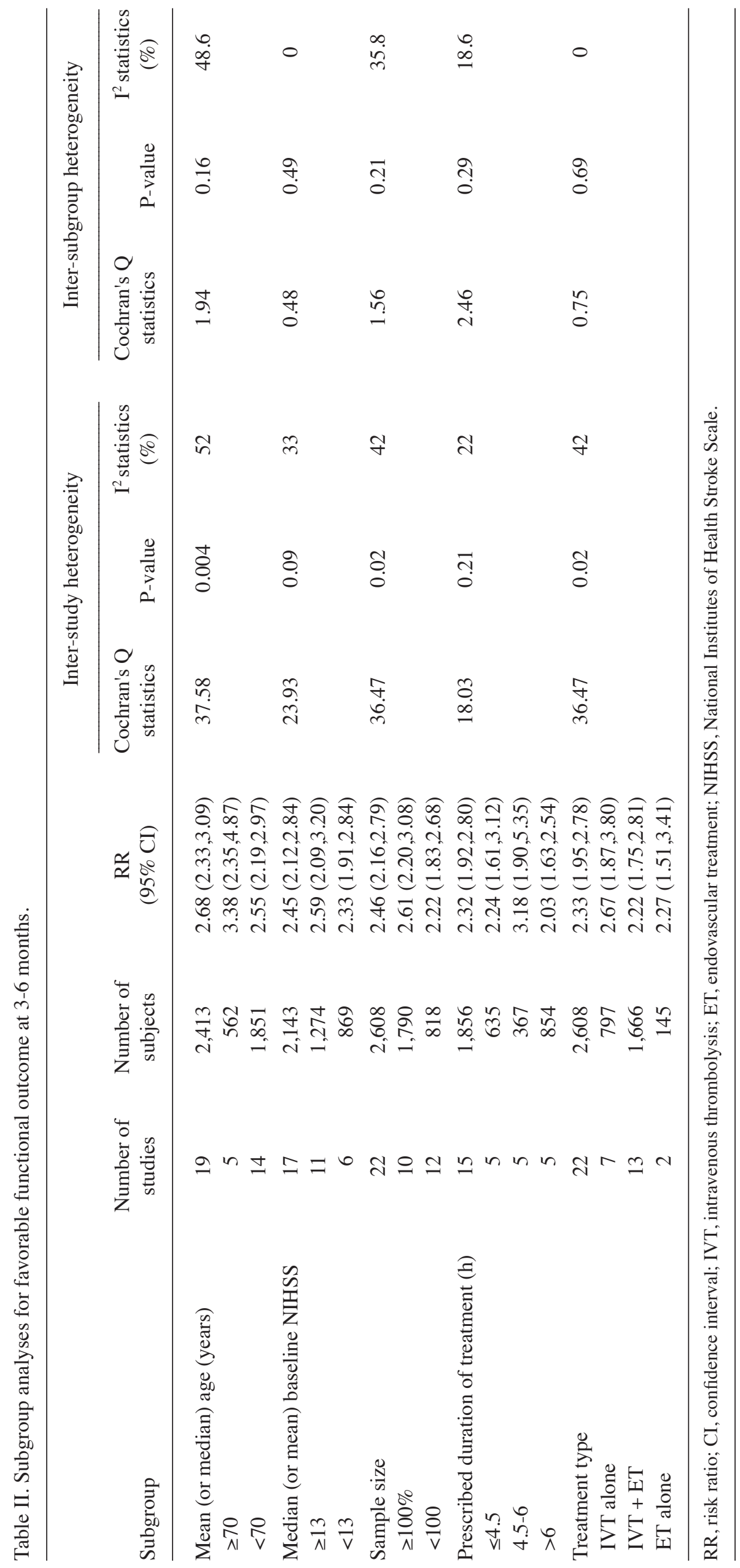




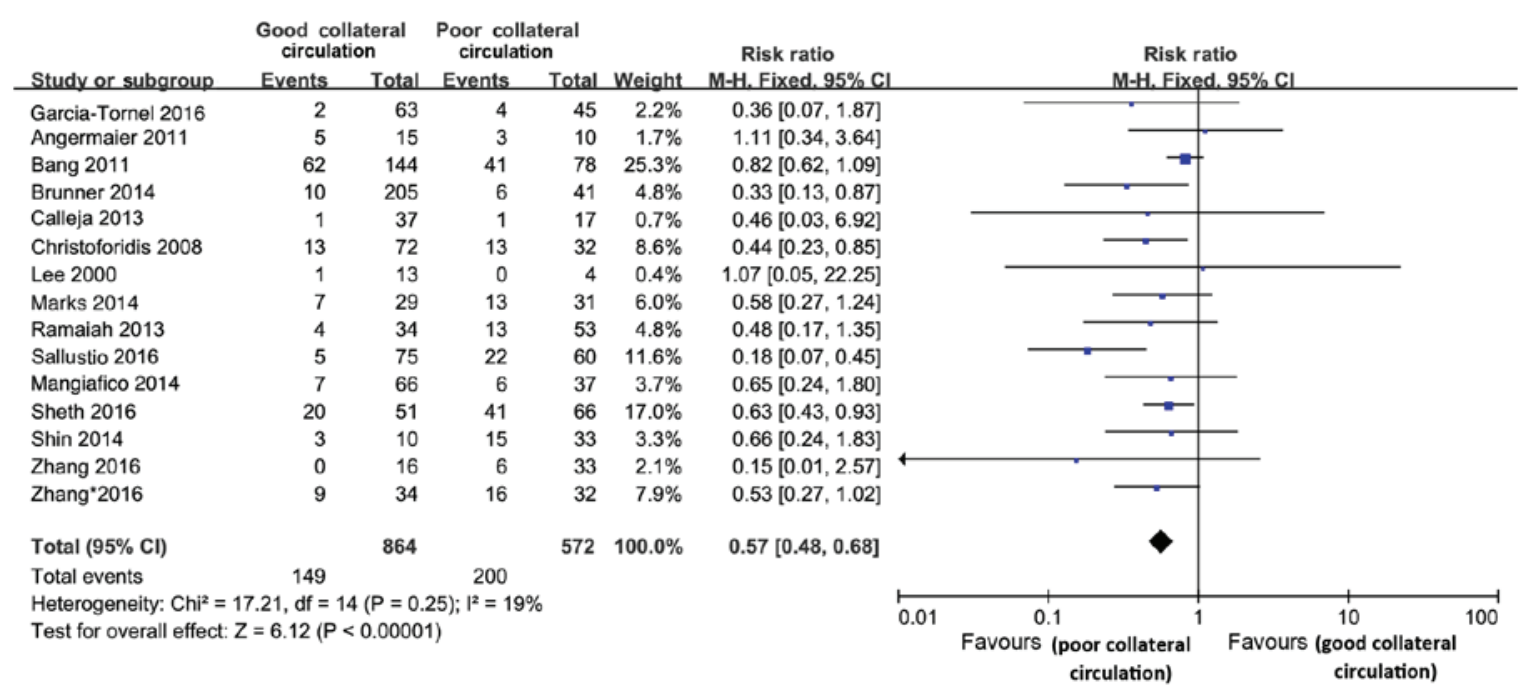

Figure 3. Forest plot presenting the estimation of the overall effects of good vs. poor pre-treatment collateral circulation status on HT. HT was defined according to the SITS-MOST definition by Calleja et al (16). HT was defined as a new hyperattenuated region identified on any follow-up CT scan before patient discharge in the study Christoforidis et al (7). HT for parenchymal hematoma formation (PH1 and PH2) was evaluated from any follow-up CT or magnetic resonance image undertaken within 7 days of stroke onset by Marks et al (24). HT, hemorrhagic transformation; CT, computed tomography; CI, confidence interval; M-H, Mantel-Haenszel; df, degrees of freedom.

\section{Discussion}

The collateral circulation connects the cerebral arteries to maintain penumbra perfusion and provide alternative routes for blood flow prior to achievement recanalization/reperfusion in patients with AIS. The predictive value of the collateral circulation status regarding the outcome in such patients has been demonstrated in various studies $(6,7,35,40-42)$; however, these studies display certain differences, including imaging evaluation methods and types of thrombolysis therapy. The literature, including baseline features of collateral status and effects of determining outcomes, was systematically reviewed in the present study. The beneficial effects of good collateral circulation regarding the favorable functional outcome at 3-6 months have been demonstrated $(12,16,26,32,43-45)$, without any significant difference among various durations of thrombolysis ( $4.5 \mathrm{~h}, 4.5-6 \mathrm{~h}$ or $>6 \mathrm{~h}$ ) and among different treatment types (ET alone, ET+IVT or IVT alone). These phenomena may be explained by the following two points: First, good collateral circulation may have improved the delivery of thrombolysis to both sides of the thrombus, while limiting any extension of the occlusion (25), facilitated adequate preservation of the penumbra until effective reperfusion was reached and increased the efficacy of aggressive ET applied to patients beyond $6 \mathrm{~h}$ as per the clinical risk of futile recanalization (46). Second, patients with poor collateral circulation status had a relatively low rate of favorable functional outcomes due to the low amount of salvageable tissue to be reperfused beyond $6 \mathrm{~h}$.

To the best of our knowledge, the present study was the first to systematically review and meta-analyze the correlation between collateral circulation status and final infarct volume. The results indicated that the collateral circulation score predicted the final infarct volume, which was negatively associated with an increased collateral blood supply that improved oligemic peri-infarct tissue perfusion to reduce infarct core expansion and maintain the viable tissue eligible for recovery of function for a prolonged duration, as also outlined in a previous study (47). According to the results of the present study, good collateral circulation also lowered the risk of HT and mortality and enhanced the rate of recanalization/reperfusion. Such effects were independent of variability in estimation methods of collateral circulation, type of thrombolysis therapy and treatment duration, which was in disagreement with the results provided by McVerry et al (48), who indicated that inconsistencies in evaluating the collateral blood flow may lead to an underestimation of the effect of the collateral circulation on the outcome of patients with AIS.

According to recent RCT studies, ET has achieved a higher efficiency as compared with IVT (49-53). The putative factors for this change are the use of stent-retriever device technology, a reduction in time delay between admission and groin puncture and the use of neuroimaging modalities for documenting vessel occlusion and patient selection (54); however, the impact of collateral status on the outcome in different treatment types had remained to be subjected to a comparative analysis. The present study revealed that good collateral circulation may have beneficial effects in both treatment types; although ET may be more effective and reliable owing to technological developments, while IVT alone also achieved favorable functional outcomes for patients with a good collateral circulation status.

Evaluation of the collateral circulation status and penumbra area prior to treatment are critical for identifying patients with AIS are likely to benefit from thrombolysis treatment. In addition, collateral circulation scores and the penumbra area should be evaluated alongside the application of the imaging methods for improved accuracy and a timely decision regarding the application of IVT. In addition, certain assessment manuals, including the Houston Intraarterial Therapy (54) and the Totaled Health Risks in Vascular Events score (55), should be jointly considered for improving the selection of patients for whom thrombolysis treatment is likely to be beneficial rather than harmful. 


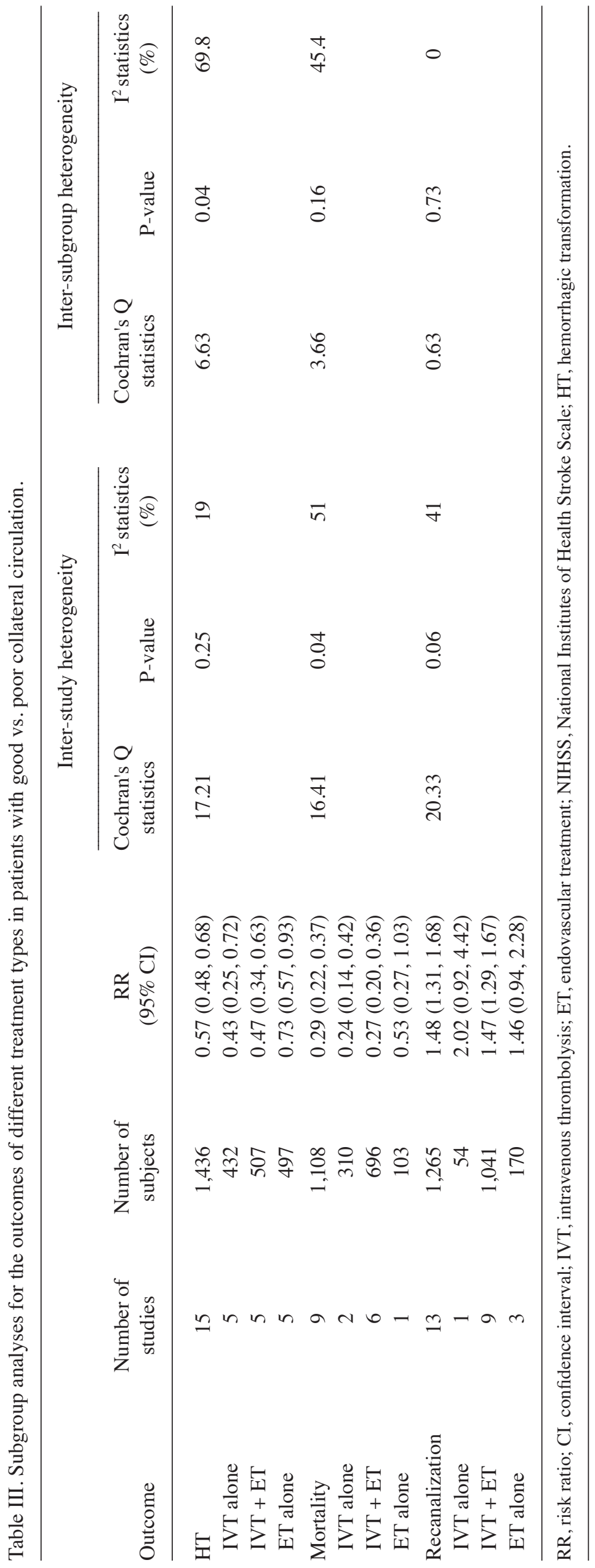




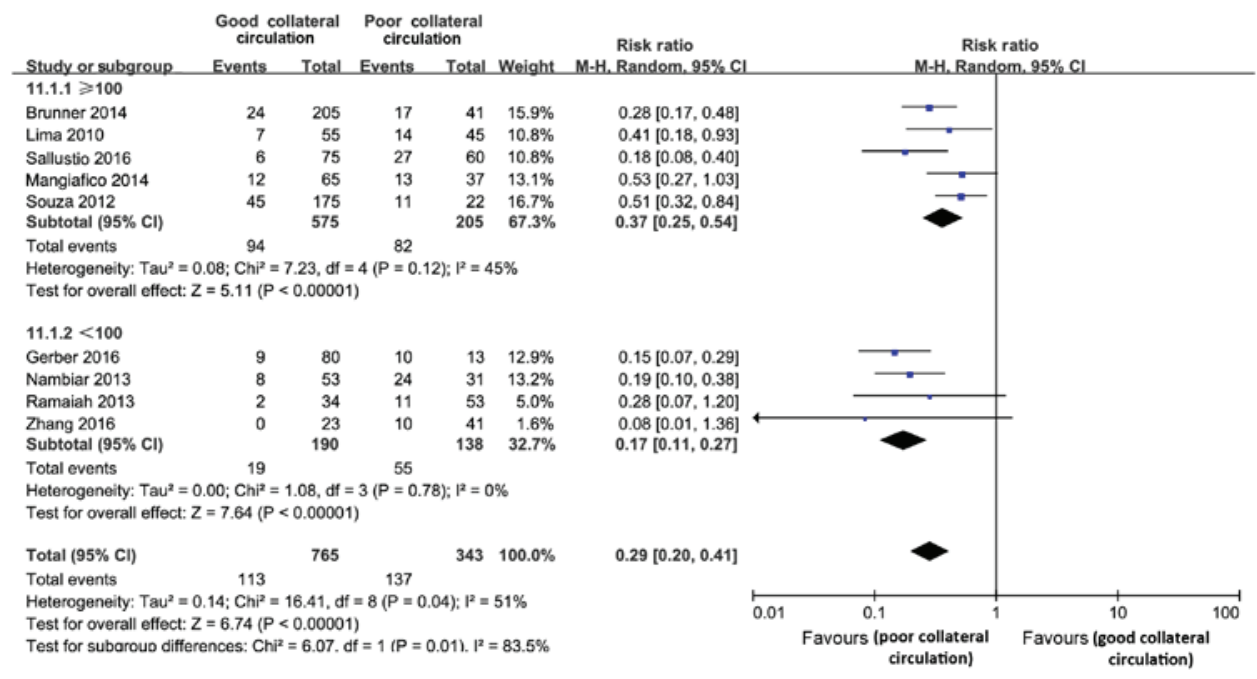

Figure 4. Forest plot presenting the estimation of the overall effects of good vs. poor pre-treatment collateral circulation status on mortality. Mortality was determined at 3 months in 6 studies, at 1 month in 1 study and at the end of the hospitalization period in 2 studies. CI, confidence interval; M-H, Mantel-Haenszel; df, degrees of freedom.

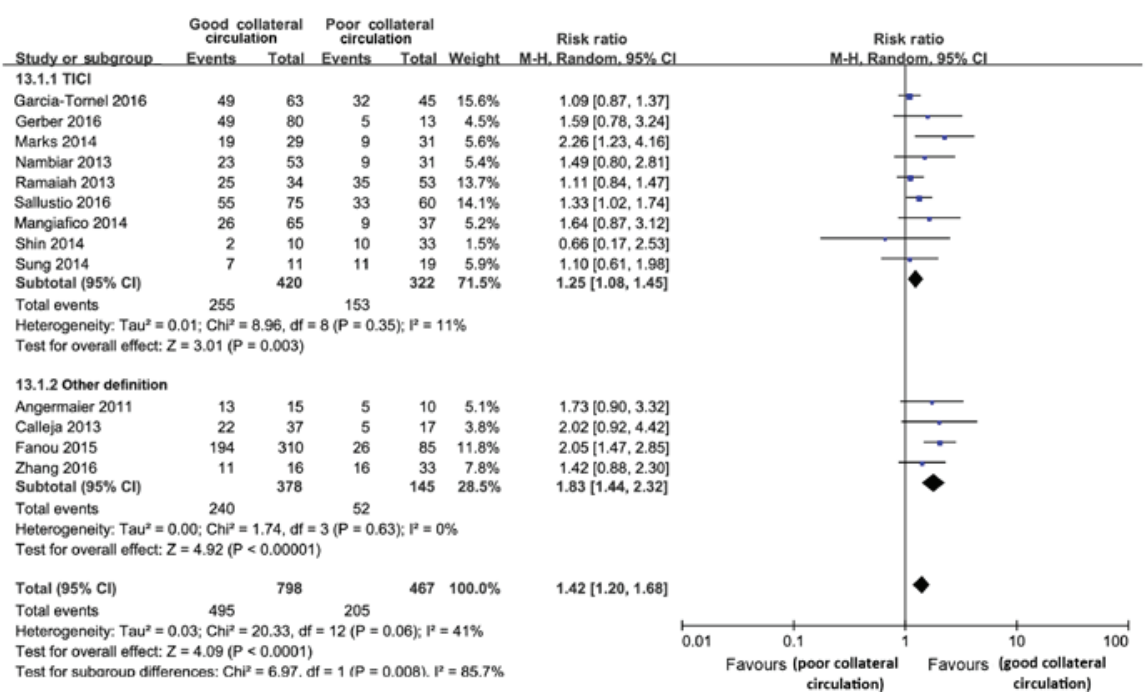

Figure 5. Forest plot presenting the estimation of the overall effects of good vs. poor pre-treatment collateral circulation status on good recanalization or reperfusion. Thrombolysis in myocardial infarction scores were 2-3 in the studies by Angermaier et al and Fanou et al (13,17), thrombolysis in brain ischemia scores were 4-5 in the study by Calleja et al (16) and arterial occlusive lesion scores were 2-3 in the study by Zhang et al (37). CI, confidence interval; M-H, Mantel-Haenszel; df, degrees of freedom; TICI, thrombolysis in cerebral infarction.

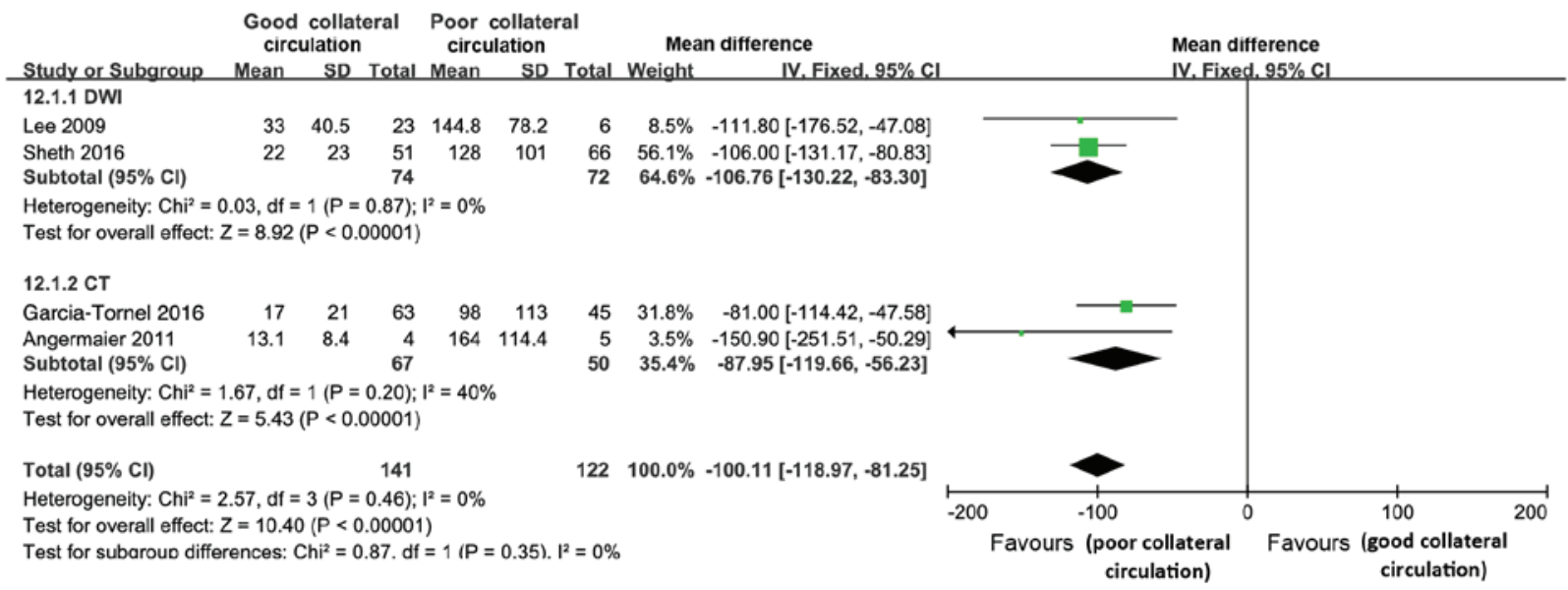

Figure 6. Forest plot presenting the estimation of the overall effects of good vs. poor pre-treatment collateral circulation status on the final infarct size. SD, standard deviation; IV, inverse variance; CI, confidence interval. 
However, the present meta-analysis had several limitations: First, the patients included in this systematic review did not only have anterior circulation ischemic stroke but also with posterior circulation ischemic stroke, which may have resulted in prognosis evaluation bias; second, the present study had other heterogeneities, including differences in ethnicity and treatment compliance after recanalization, and the effects of good collateral circulation are probably restricted to certain subgroups of patients, which requires further exploration. Third, a sampling bias may have been present, as an English language restriction was imposed on the literature search due to which the studies published in other languages were neither identified nor included, thereby reducing the broadness of the analysis. Also, in the present study the effect was more significant in the subgroup of other definitions (TIMI, TIBI or AOL scores) than in the TICI subgroup. The number of studies included in the two groups was different, therefore resulting in a bias between the two groups. Unifying the evaluation and reporting standards for revascularization would benefit horizontal and longitudinal comparisons among IVT or ET studies in the future.

In conclusion, a good collateral circulation status may lead to a favorable 3-6-month functional outcome, a better recanalization or reperfusion rate, a smaller infarct core, a lower HT rate and a lower risk of mortality after thrombolysis treatment for various durations in patients with AIS. In clinical practice, it may be worth considering the collateral circulation status, penumbra assessment and onset-to-treatment time for optimally identifying suitable patients who are likely to benefit from thrombolysis treatment.

\section{References}

1. Hankey GJ: Stroke. Lancet 389: 641-654, 2016.

2. Angermaier A, Langer S, Kirsch M, Kessler C, Hosten N and Khaw AV: CT-angiographic collateralization predicts final infarct volume after intra-arterial thrombolysis for acute anterior circulation ischemic stroke. Cerebrovasc Dis 31: 177-184, 2011.

3. Shuaib A, Butcher K, Mohammad AA, Saqqur M and Liebeskind DS: Collateral blood vessels in acute ischaemic stroke: A potential therapeutic target. Lancet Neurol 10: 909-921, 2011.

4. Ribo M, Flores A, Rubiera M, Pagola J, Sargento-Freitas J, Rodriguez-Luna D, Coscojuela P, Maisterra O, Piñeiro S, Romero FJ, et al: Extending the time window for endovascular procedures according to collateral pial circulation. Stroke 42: 3465-3469, 2011.

5. Bang OY, Goyal M and Liebeskind DS: Collateral circulation in ischemic stroke: Assessment tools and therapeutic strategies. Stroke 46: 3302-3309, 2015.

6. Bang OY, Saver JL, Kim SJ, Kim GM, Chung CS, Ovbiagele B, Lee KH and Liebeskind DS: Collateral flow predicts response to endovascular therapy for acute ischemic stroke. Stroke 42: 693-699, 2011.

7. Christoforidis GA, Karakasis C, Mohammad Y, Caragine LP, Yang M and Slivka AP: Predictors of hemorrhage following intra-arterial thrombolysis for acute ischemic stroke: The role of pial collateral formation. AJNR Am J Neuroradiol 30: 165-170, 2009.

8. Bang OY, Saver JL, Kim SJ, Kim GM, Chung CS, Ovbiagele B, Lee KH and Liebeskind DS; UCLA-Samsung Stroke Collaborators: Collateral flow averts hemorrhagic transformation after endovascular therapy for acute ischemic stroke. Stroke 42 : 2235-2239, 2011

9. Leng X, Lan L, Liu L, Leung TW and Wong KS: Good collateral circulation predicts favorable outcomes in intravenous thrombolysis: A systematic review and mate-analysis. Eur J Neurol 23: $1738-1749,2016$
10. Moher D, Liberati A, Tetzlaff J and Altman DG; PRISMA Group: Preferred reporting items for systematic reviews and meta-analyses: The PRISMA statement. Ann Intern Med 151: 264-269, W64, 2009.

11. Stroup DF, Berlin JA, Morton SC, Olkin I, Williamson GD, Rennie D, Moher D, Becker BJ, Sipe TA and Thacker SB: Meta-analysis of observational studies in epidemiology: A proposal for reporting. Meta-analysis of observational studies in epidemiology (MOOSE) group. JAMA 283: 2008-2012, 2000.

12. García-Tornel A, Carvalho V, Boned S, Flores A, Rodríguez-Luna D, Pagola J, Muchada M, Sanjuan E, Coscojuela P, Juega J, et al: Improving the evaluation of collateral circulation by multiphase computed tomography angiography in acute stroke patients treated with endovascular reperfusion therapies. Interv Neurol 5: 209-217, 2016.

13. Angermaier A, Langner S, Kirsch M, Kessler C, Hosten N and Khaw AV: CT-angiographic collateralization predicts final infarct volume after intra-arterial thrombolysis for acute anterior circulation ischemic stroke. Cerebrovasc Dis 31: 177-184, 2011.

14. Berkhemer OA, Jansen IG, Beumer D, Fransen PS, van den Berg LA, Yoo AJ, Lingsma HF, Sprengers ME, Jenniskens SF, Lycklama À Nijeholt GJ, et al: Collateral status on baseline computed tomographic angiography and intra-arterial treatment effect in patients with proximal anterior circulation stroke. Stroke 47: 768-776, 2016.

15. Brunner F, Tomandl B, Hanken K, Hildebrandt H and Kastrup A: Impact of collateral circulation on early outcome and risk of hemorrhagic complications after systemic thrombolysis. Int J Stroke 9: 992-998, 2014.

16. Calleja AI, Cortijo E, García-Bermejo P, Gómez RD, Pérez-Fernández S, Del Monte JM, Muñoz MF, FernándezHerranz R and Arenillas JF: Collateral circulation on perfusion-computed tomography-source images predicts the response to stroke intravenous thrombolysis. Eur J Neurol 20: 795-802, 2013.

17. Fanou EM, Knight J, Aviv RI, Hojjat SP, Symons SP, Zhang L and Wintermark M: Effect of collaterals on clinical presentation, baseline imaging, complications, and outcome in acute stroke. AJNR Am J Neuroradiol 36: 2285-2291, 2015.

18. Gerber JC, Petrova M, Krukowski P, Kuhn M, Abramyuk A, Bodechtel U, Dzialowski I, Engellandt K, Kitzler H, Pallesen LP, et al: Collateral state and the effect of endovascular reperfusion therapy on clinical outcome in ischemic stroke patients. Brain Behav 6: e00513, 2016.

19. Kufner A, Galinovic I, Ambrosi V, Nolte CH, Endres M, Fiebach JB and Ebinger M: Hyperintense vessels on FLAIR: Hemodynamic correlates and response to thrombolysis. AJNR Am J Neuroradiol 36: 1426-1430, 2015.

20. Lee KH, Lee SJ, Cho SJ, Na DG, Byun HS, Kim YB, Song HJ, Jin IS and Chung CS: Usefulness of triphasic perfusion computed tomography for intravenous thrombolysis with tissue-type plasminogen activator in acute ischemic stroke. Arch Neurol 57: 1000-1008, 2000.

21. Lee KY, Latour LL, Luby M, Hsia AW, Merino JG and Warach S: Distal hyperintense vessels on FLAIR: An MRI marker for collateral circulation in acute stroke? Neurology 72: 1134-1139, 2009.

22. Lima FO, Furie KL, Silva GS, Lev MH, Camargo EC, Singhal AB, Harris GJ, Halpern EF, Koroshetz WJ, Smith WS, et al: The pattern of leptomeningeal collaterals on CT angiography is a strong predictor of long-term functional outcome in stroke patients with large vessel intracranial occlusion. Stroke 41: 2316-2322, 2010.

23. Menon BK, Qazi E, Nambiar V, Foster LD, Yeatts SD, Liebeskind D, Jovin TG, Goyal M, Hill MD, Tomsick TA, et al: Differential effect of baseline computed tomographic angiography collaterals on clinical outcome in patients enrolled in the interventional management of stroke III trial. Stroke 46: 1239-1244, 2015.

24. Marks MP, Lansberg MG, Mlynash M, Olivot JM, Straka M, Kemp S, McTaggart R, Inoue M, Zaharchuk G, Bammer R, et al: Effect of collateral blood flow on patients undergoing endovascular therapy for acute ischemic stroke. Stroke 45: 1035-1039, 2014.

25. Miteff F, Levi CR, Bateman GA, Spratt N, McElduff P and Parsons MW: The independent predictive utility of computed tomography angiographic collateral status in acute ischaemic stroke. Brain 132: 2231-2238, 2009. 
26. Nambiar V, Sohn SI, Almekhlafi MA, Chang HW, Mishra S Qazi E, Eesa M, Demchuk AM, Goyal M, Hill MD and Menon BK: CTA collateral status and response to recanalization in patients with acute ischemic stroke. AJNR Am J Neuroradiol 35: 884-890, 2014.

27. Ramaiah SS, Churilov L, Mitchell P, Dowling R and Yan B: The impact of arterial collateralization on outcome after intra-arterial therapy for acute ischemic stroke. AJNR Am J Neuroradiol 35: 667-672, 2014

28. Saarinen JT, Rusanen H and Sillanpää N: Collateral score complements clot location in predicting the outcome of intravenous thrombolysis. AJNR Am J Neuroradiol 35: 1892-1896, 2014.

29. Sallustio F, Motta C, Pizzuto S, Diomedi M, Giordano A, D'Agostino VC, Samà D, Mangiafico S, Saia V, Legramante JM, et al: CT angiography-based collateral flow and time to reperfusion are strong predictors of outcome in endovascular treatment of patients with stroke. J Neurointerv Surg 9: 940-943, 2017.

30. Mangiafico S, Saia V, Nencini P, Romani I, Palumbo V, Pracucci G, Consoli A, Rosi A, Renieri L, Nappini S, et al: Effect of the interaction between recanalization and collateral circulation on functional outcome in acute ischaemic stroke. Interv Neuroradiol 20: 704-714, 2014

31. van Seeters T, Biessels GJ, Kappelle LJ, van der Graaf Y and Velthuis BK; Dutch acute stroke study (DUST) investigators: Determinants of leptomeningeal collateral flow in stroke patients with a middle cerebral artery occlusion. Neuroradiology 58 969-977, 2016.

32. Sheth SA, Sanossian N, Hao Q, Starkman S, Ali LK, Kim D, Gonzalez NR, Tateshima S, Jahan R, Duckwiler GR, et al: Collateral flow as causative of good outcomes in endovascular stroke therapy. J Neurointerv Surg 8: 2-7, 2016.

33. Shin NY, Kim KE, Park M, Kim YD, Kim DJ, Ahn SJ, Heo JH and Lee SK: Dual-phase CT collateral score: A predictor of clinical outcome in patients with acute ischemic stroke. PLoS One 9: e107379, 2014.

34. Souza LC, Yoo AJ, Chaudhry ZA, Payabvash S, Kemmling A, Schaefer PW, Hirsch JA, Furie KL, González RG, Nogueira RG and Lev MH: Malignant CTA collateral profile is highly specific for large admission DWI infarct core and poor outcome in acute stroke. AJNR Am J Neuroradiol 33: 1331-1336, 2012.

35. Sung SM, Lee TH, Cho HJ, Kang TH, Jung DS, Park KP, Park MK, Lee JI and Ko JK: Functional outcome after recanalization for acute pure M1 occlusion of the middle cerebral artery as assessed by collateral CTA flow. Clin Neurol Neurosurg 131: 72-76, 2015.

36. Yeo LL, Paliwal P, Teoh HL, Seet RC, Chan BP, Ting E, Venketasubramanian N, Leow WK, Wakerley B, Kusama Y, et al: Assessment of intracranial collaterals on CT angiography in anterior circulation acute ischemic stroke. AJNR Am J Neuroradiol 36: 289-294, 2015

37. Zhang S, Chen W, Tang H, Han Q, Yan S, Zhang X, Chen Q, Parsons M, Wang S and Lou M: The prognostic value of a four-dimensional CT angiography-based collateral grading scale for reperfusion therapy in acute ischemic stroke patients. PLoS One 11: $\mathrm{e} 0160502,2016$.

38. Zhang S, Zhang X, Yan S, Lai Y, Han Q, Sun J, Zhang M, Parsons MW, Wang S and Lou M: The velocity of collateral filling predicts recanalization in acute ischemic stroke after intravenous thrombolysis. Sci Rep 6: 27880, 2016.

39. Hacke W, Kaste M, Fieschi C, von Kummer R, Davalos A, Meier D, Larrue V, Bluhmki E, Davis S, Donnan G, et al: Randomised double-blind placebo-controlled trial of thrombolytic therapy with intravenous alteplase in acute ischaemic stroke (ECASS II). Second European-Australasian acute stroke study investigators. Lancet 352: 1245-1251, 1998.

40. Ito M, Yoshimoto T, Kawabori M, Fujimoto S, Yamauchi T, Yamaguchi H, Tokuda K and Kaneko S: Diagnostic impact of baseline cerebral blood flow in patients with acute ischemic stroke prior to intravenous recombinant tissue plasminogen activator therapy. Clin Neurol Neurosurg 115: $1464-1469,2013$
41. Liebeskind DS: Imaging the future of stroke: I. Ischemia. Ann Neurol 66: 574-590, 2009.

42. Liebeskind DS and Alexandrov AV: Advanced multimodal CT/MRI approaches to hyperacute stroke diagnosis, treatment, and monitoring. Ann N Y Acad Sci 1268: 1-7, 2012.

43. Mangiafico S, Saia V, Nencini P, Romani I, Palumbo V, Pracucci G, Consoli A, Rosi A, Renieri L, Nappini S, et al: Effect of the interaction between recanalization and collateral circulation on functional outcome in acute ischaemic stroke. Interv Neuroradiol 20: 704-714, 2014.

44. Beyer SE, Thierfelder KM, von Baumgarten L, Rottenkolber M, Meinel FG, Janssen H, Ertl-Wagner B, Reiser MF and Sommer WH: Strategies of collateral blood flow assessment in ischemic stroke: Prediction of the follow-up infarct volume in conventional and dynamic CTA. AJNR Am J Neuroradiol 36: 488-494, 2015.

45. Ernst M, Forkert ND, Brehmer L, Thomalla G, Siemonsen S, Fiehler J and Kemmling A: Prediction of infarction and reperfusion in stroke by flow- and volume-weighted collateral signal in MR angiography. AJNR Am J Neuroradiol 36: 275-282, 2015.

46. Jickling GC, Liu D, Stamova B, Ander BP, Zhan X, Lu A and Sharp FR: Hemorrhagic transformation after ischemic stroke in animals and humans. J Cereb Blood Flow Metab 34: 185-199, 2014.

47. Arnold M, Schroth G, Nedeltchev K, Loher T, Remonda L, Stepper F, Sturzenegger M and Mattle HP: Intra-arterial thrombolysis in 100 patients with acute stroke due to middle cerebral artery occlusion. Stroke 33: 1828-1833, 2002.

48. McVerry F, Liebeskind DS and Muir KW: Systematic review of methods for assessing leptomeningeal collateral flow. AJNR Am J Neuroradiol 33: 576-582, 2012.

49. Goyal M, Demchuk AM, Menon BK, Eesa M, Rempel JL, Thornton J, Roy D, Jovin TG, Willinsky RA, Sapkota BL, et al: Randomized assessment of rapid endovascular treatment of ischemic stroke. N Engl J Med 372: 1019-1030, 2015.

50. Campbell BC, Mitchell PJ, Kleinig TJ, Dewey HM, Churilov L, Yassi N, Yan B, Dowling RJ, Parsons MW, Oxley TJ, et al: Endovascular therapy for ischemic stroke with perfusion-imaging selection. N Engl J Med 372: 1009-1018, 2015.

51. Berkhemer OA, Fransen PS, Beumer D, van den Berg LA, Lingsma HF, Yoo AJ, Schonewille WJ, Vos JA, Nederkoorn PJ, Wermer MJ, et al: A randomized trial of intraarterial treatment for acute ischemic stroke. N Engl J Med 372: 11-20, 2015.

52. Saver JL, Goyal M, Bonafe A, Diener HC, Levy EI, Pereira VM, Albers GW, Cognard C, Cohen DJ, Hacke W, et al: Stent-retriever thrombectomy after intravenous t-PA vs. t-PA alone in stroke. N Engl J Med 372: 2285-2295, 2015.

53. Jovin TG, Chamorro A, Cobo E, de Miquel MA, Molina CA, Rovira A, Román LS, Serena J, Abilleira S, Ribó M, et al: Thrombectomy within $8 \mathrm{~h}$ after symptom onset in ischemic stroke. N Engl J Med 372: 2296-2306, 2015.

54. Hallevi H, Barreto AD, Liebeskind DS, Morales MM, Martin-Schild SB, Abraham AT, Gadia J, Saver JL; UCLA Intra-Arterial Therapy Investigators, Grotta JC and Savitz SI: Identifying patients at high risk for poor outcome after intra-arterial therapy for acute ischemic stroke. Stroke 40: 1780-1785, 2009.

55. Flint AC, Kamel H, Rao VA, Cullen SP, Faigeles BS and Smith WS: Validation of the totaled health risks in vascular events (THRIVE) score for outcome prediction in endovascular stroke treatment. Int J Stroke 9: 32-39, 2014.

This work is licensed under a Creative Commons Attribution-NonCommercial-NoDerivatives 4.0 International (CC BY-NC-ND 4.0) License. 